\title{
Altitude May Contribute to Regional Variation in Methamphetamine Use in the United States: A Population Database Study
}

\author{
Tae-Suk Kim ${ }^{1,2,3} \bowtie$, Douglas G Kondo ${ }^{1,2,4}$, Namkug Kim ${ }^{5}$, and Perry F Renshaw ${ }^{1,2,4}$ \\ ${ }^{1}$ The Brain Institute, University of Utah, Salt Lake City, UT, USA \\ ${ }^{2}$ Department of Psychiatry, University of Utah School of Medicine, Salt Lake City, UT, USA \\ ${ }^{3}$ Department of Psychiatry, The Catholic University of Korea College of Medicine, Seoul, Republic of Korea \\ ${ }^{4}$ VISN 19 MIRECC, Salt Lake City Veterans Affairs Health Care System, Salt Lake City, UT, USA \\ ${ }^{5}$ Department of Radiology and Research Institute of Radiology, University of Ulsan College of Medicine, Seoul, Republic of Korea
}

\begin{abstract}
Objective Methamphetamine (MA) use rates in the United States (US) have consistently demonstrated geographical variation and have been higher in the West and Midwest. This uneven pattern of use could be explained by regional differences in MA manufacturing and distribution, but may also result from differences in altitude. The hypobaric hypoxia found at high altitude alters neurotransmitter synthesis in the brain, which may contribute to MA use. The present study investigated the relationship between mean altitude and MA use rate in the 48 contiguous US states and the District of Columbia.

Methods State-level estimates of past year MA use were extracted from the National Survey on Drug Use and Health report. The mean altitude of each state was calculated using the Shuttle Radar Topography Mission altitude data set.

Results There was a significant positive correlation between mean state altitude and MA use rate $(r=0.66, p<0.0001)$. Multivariate linear regression analysis showed that altitude remained a significant predictor for MA use rate $(\beta=0.36, p=0.02)$, after adjusting for age, ethnicity, education, socioeconomic level, employment, MA laboratory incidents, subpopulations, and other substance use.

Conclusion Altitude appears to a possible contributing factor for regional variation of MA use in the US. Further studies will be required to determine biological changes in neurotransmission resulting from chronic mild hypoxia at high altitude in MA users.
\end{abstract}

Psychiatry Investig 2014;11(4):430-436

Key Words Altitude, Elevation, Hypoxia, Methamphetamine, Neurotransmission.

\section{INTRODUCTION}

Methamphetamine (MA) is a highly addictive and powerful sympathomimetic drug that directly affects the central nervous system as well as the autonomic nervous system, even when taken in small amounts. ${ }^{1}$ Repeated MA use has been shown to cause persistent dopaminergic deficits resulting in long-term neurological damage ${ }^{2}$ and leads to clinically significant social, occupational, and medical impairment. ${ }^{3}$ Despite federal and international regulations designed to tighten control of precursor materials needed for the synthesis of MA, ${ }^{4}$

Received: October 25, 2013 Revised: January 17, 2014

Accepted: January 20, 2014 Available online: October 20, 2014

$\triangle$ Correspondence: Tae-Suk Kim, MD, PhD

Department of Psychiatry, The Catholic University of Korea College of Medicine, 222 Banpo-daero, Seocho-gu, Seoul 137-701, Republic of Korea

Tel: +82-2-2258-6085, Fax: +82-2-594-3870

E-mail: bluenote@catholic.ac.kr

(a) This is an Open Access article distributed under the terms of the Creative Commons Attribution Non-Commercial License (http://creativecommons.org/licenses/bync/3.0) which permits unrestricted non-commercial use, distribution, and reproduction in any medium, provided the original work is properly cited. there is no decrease of MA use in the US and throughout the world. MA abuse and dependence have become major public health and law enforcement problems. ${ }^{5}$

MA use in the US has been demonstrated to have regional variation and has consistently been higher in the West and Midwest. ${ }^{5,6}$ One explanation for this relationship may be regional differences in MA manufacturing and distribution. First, since 1990, the manufacture and distribution of MA has expanded in two major ways. MA production in home laboratories became widespread throughout California and other Western states, as well as in the Rocky Mountain states. At the same time, large-scale laboratories developed in Southern California and Northern Mexico. MA from these labs was distributed primarily in the West and Midwest. ${ }^{5,7}$ MA supply from these two sources resulted in a higher availability of MA throughout the West and Midwest. However, these factors do not completely explain the regional variation in MA use. The West and Midwest hold consistently higher rates of MA use though current MA production and distribution are more 
geographically dispersed in the United States. ${ }^{6,8}$

The etiology of MA use disorders is not clear, but has been suggested to involve multiple factors including the psychoactive properties of MA, individual differences such as genetics and personality, and environmental variables. ${ }^{9}$ Among these factors, environmental stressors may be potent initial motivators for MA use as well as modulators of MA recurrence and maintenance. ${ }^{10}$ Heritability is defined as the variance in a disease trait that can be attributed to genetic factors, with the remainder accounted for by the environment. While the heritability of MA abuse and dependence are unknown, several studies have examined the stimulant class of drugs that includes MA and cocaine. ${ }^{11,12}$ In these studies, $33-79 \%$ of the variance in the risk for stimulant use disorders is attributable to genetic factors, indicating that up to $67 \%$ can be attributed to environmental factors.

One potential environmental contributor to the regional variation in MA use may be the effect of high altitude, which is a major geographic characteristic of the Intermountain West in the US Increased altitudes provide sustained hypobaric and hypoxic environments. The brain consumes 20 percent of the total body oxygen for its normal neurophysiological function. ${ }^{13}$ The rate-limiting enzymes related to the synthesis of neurotransmitters including dopamine (DA), serotonin (5$\mathrm{HT}$ ), and norepinephrine (NE) are highly oxygen-dependent and require sufficient oxygen for their optimal activity. ${ }^{14}$ Thus, even mild hypoxia could impact neurotransmitter synthesis, potentially altering neurophysiological function..$^{13}$ Although the brain works to maintain neuronal function despite the hypoxic insult associated with altitude, ${ }^{15}$ a growing body of evidence demonstrates that the homeostasis of the neurotransmitter systems in the brain is altered in the course of time at high altitude. In preclinical studies, exposure to hypobaric hypoxia for periods of 7 and 14 days has been reported to increase DA levels and decrease 5-HT levels in the frontal lobe. ${ }^{16}$ It has also been shown that simulated altitude increases the lethality of methamphetamine, but does not affect the lethality of sympathomimetic amines that act peripherally rather than centrally. ${ }^{17}$

Altered functioning of brain DA and 5-HT systems may play a role in MA use disorders. Psychostimulant abuse vulnerability has been linked to chronic exposure to stress, ${ }^{18}$ personality factors including sensation/novelty seeking and impulsivity, ${ }^{19,20}$ and their genetic predisposition, ${ }^{21,22}$ which are characterized by dopaminergic hyperactivity and/or serotonergic hypoactivity. ${ }^{23,24}$ Enhanced DA levels are also implicated in cross-behavioral sensitization between MA and cocaine. ${ }^{25}$ Cocaine and amphetamines are powerful psychostimulants that cause euphoria, heightened alertness, increased energy and intensified emotions. These effects are mediated by in- creased synaptic concentrations of monoamines including DA, 5-HT, and NE. ${ }^{26,27}$ It is now well-established that the reinforcing effect of drugs depends not only on striatal DA increases, but on the rate of such increases. ${ }^{28}$ Given the cross-tolerance between MA and cocaine, ${ }^{29}$ the recognized effects of altitude on DA levels and MA lethality, and our finding that altitude is a predictor of cocaine use, ${ }^{30}$ we sought to investigate the possibility of a relationship between altitude and MA use.

The majority of worldwide MA production and consumption now occurs in Southeast Asia and North America. ${ }^{31}$ With the epidemiologic and potential neurobiological connections between high altitude of residence and MA use, we hypothesized that altitude would have a significant association with the rate of MA use in the US In this study, we investigated the relationship between the state-level MA and other substance use data from National Survey on Drug Use and Health (NSDUH) and mean state altitude in the US Also, to increase the credibility of our hypothesis, we performed a multivariate regression analysis of MA use rate with mean altitude and previously reported risk factors affecting MA use $\mathrm{e}^{5,32,33}$ by state level.

\section{METHODS}

\section{Methamphetamine use data}

State-level estimates of 12-month prevalence of MA use were extracted from the 2002 to 2005 National Survey on Drug Use and Health (NSDUH) report sponsored by the Substance Abuse and Mental Health Services Administration (SAMHSA) ${ }^{34}$ The NSDUH provides national and state-level data on the use of tobacco, alcohol, illicit drugs, and mental health variables in the U.S. The NSDUH survey is annually conducted in all 50 states and the District of Columbia, and involves telephone interviews with approximately 70,000 randomly selected individuals aged 12 and older. During the interval 2002-2005, approximately 1.4 million persons (0.60 percent of the total population) aged 12 or older estimated using MA in the past year. The highest and lowest rates of state-level MA use were $2.02 \%$ in Nevada and $0.06 \%$ in Connecticut, respectively (Figure 1).

\section{Average state altitude data}

Average state-level altitude in the U.S. was calculated using the Shuttle Radar Topography Mission (SRTM) altitude data set. ${ }^{35}$ The SRTM dataset is a high-resolution global scale digital topographic database of the Earth covering virtually entire land surface between $\pm 60^{\circ}$ latitudes. With $0.1 \mathrm{~km}$ spatial resolution, the mean altitude of each county in the US can be accurately calculated. County outlines from the National Atlas of the United States (NAUS): County Boundaries of the United States $^{36}$ were used to obtain the mean county altitude based 


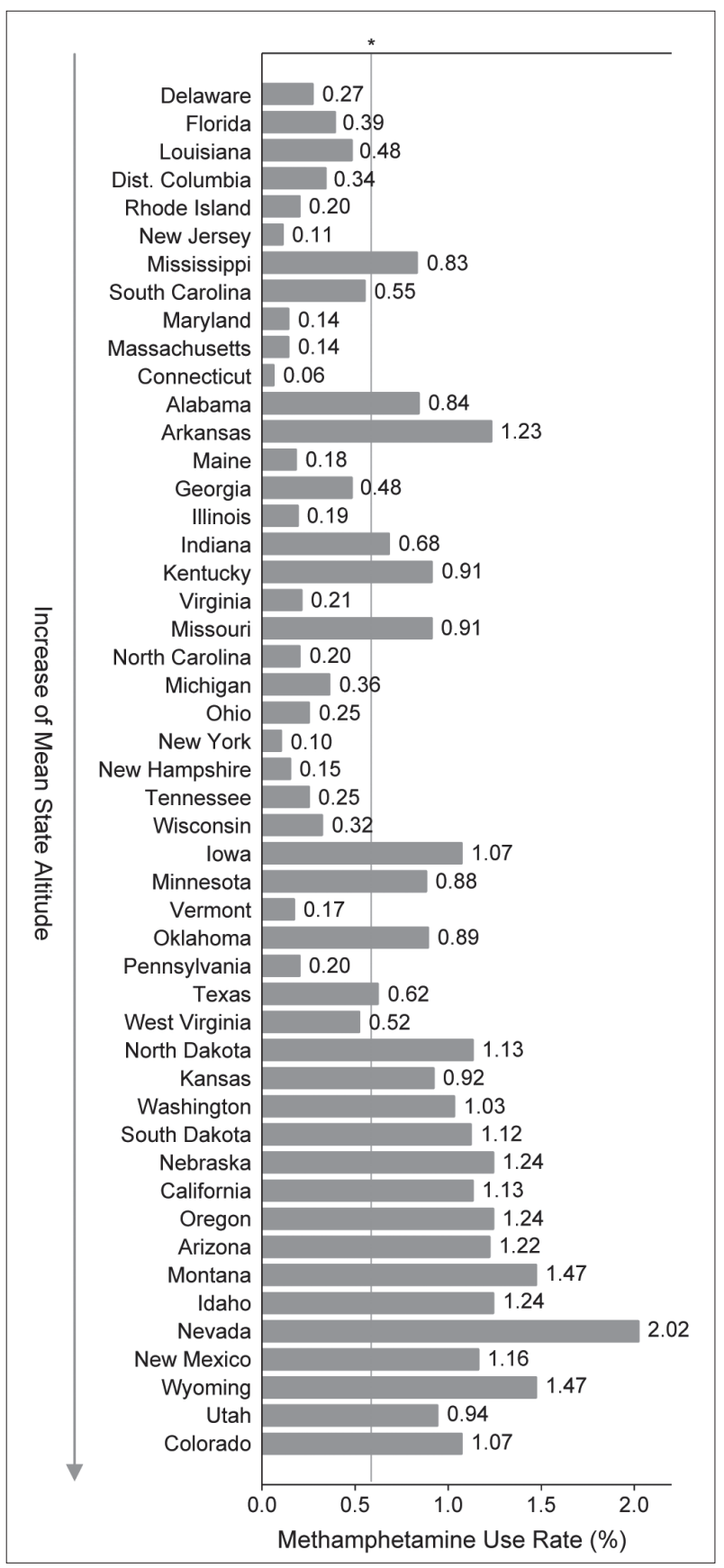

Figure 1. Percentages of persons aged 12 or older reporting past year methamphetamine use by state in 2002-2005**. *mean methamphetamine use rate in the past year in the United States in $2002-2005(0.60 \%)$,**based on 48 contiguous states and the District of Columbia (excludes Alaska and Hawaii).

on the SRTM mean altitude calculations for each square kilometer. Four counties were not included in this NAUS data set; one each in Montana and Georgia and two in Virginia. These counties are not included in the analysis. The average altitude of each county ( $n=3108)$ in 48 contiguous states and the District of Columbia except Alaska and Hawaii was calculated using zonal statistics in an ArcGIS/ArcInfo 9.3 environment
(ESRI, Redlands, CA, USA). The ArcGIS/ArcInfo software is a full-featured geographic information system for geographical database mapping. Each average state altitude was calculated using below formula;

$$
\sum_{(\mathrm{i}=1)}^{\mathrm{n}}(\text { mean county altitude }) \mathrm{i} \times(\text { area of county }) \mathrm{i}
$$

\section{Potential confounders}

Potential confounding variables affecting MA use were obtained from previous studies. ${ }^{5,32,33}$ State-level sociodemographic characteristics (population density, age, race, education, employment, and economic status), other substance use (cocaine, heroin, marijuana, alcohol, tobacco, and nonmedical use of prescription pain relievers), MA laboratory incidents, and subpopulations were included as confounders. Gender as a confounder was excluded from the analysis model because MA has been reported to appeal fairly equally to both men and women. ${ }^{6,37}$ We obtained data from the 2010 Census on individual sociodemographic state-level variables, including: age under 18 years; White, Black, Hispanic, Asian, and American Indian (AI) and Alaska Native (AN) populations; persons aged 25 or over who are high school graduates; and median household income. ${ }^{38}$ Average state unemployment rate data was acquired from the Bureau of Labor Statistics (BLS) in the United States Department of Labor. ${ }^{39}$ State-level cocaine, heroin, marijuana, alcohol, tobacco, and nonmedical prescription pain reliever use rates were extracted from the NSDUH. The state-level number of MA laboratory incidents in 2004 was extracted from the National Clandestine Laboratory Seizure System of Drug Enforcement Administration (DEA) affiliated with the US Department of Justice. ${ }^{40}$ Incidents entered into this system are classified in one of three ways: Operational Laboratories, Chemical/Equipment/Glassware seizures, and Dumpsites. The manufacturing and distribution of MA are likely to reflect the number of MA laboratory incidents. The total number of MA laboratory incidents in the US was 18,091 in 2004. The highest number of incidents by state was 2,820 in Missouri, while no incidents were reported in Rhode Island. State-level MA laboratory incident rates were defined as the number of incidents per 100,000 population. The number of same sex couples per 1,000 households by state, which may be regarded as a possible high risk subpopulation for MA use, ${ }^{7}$ was obtained from the Williams Institute analysis of 2010 Census data. ${ }^{41}$

\section{Data analysis}

The Kolmogorov-Smirnov test was performed on each variable to test for normality of the distribution in the data. The data for mean state altitude, Hispanic population percent- 
age, percentage of AI and AN population, MA laboratory incidents per 100,000 people and heroin use rate showed skewed distributions. Thus, logarithmic $(\log )$ transformation of these data was carried out before correlation and regression analyses. Because MA laboratory incidents per 100,000 population for Rhode Island were 0 , this was changed to 0.0001 before $\log$ transformation. Sensitivity analysis demonstrated that this change did not alter the results.

Pearson correlation coefficients were calculated to investigate the association between MA use rate and log transformed mean state altitude. A simple linear regression analysis was performed to analyze MA use rate as the dependent variable, and transformed mean state altitude as the independent variable.

To increase confidence in the significance of our results, we performed an additional analysis that controlled for the effects of a number of possible covariates. Because this analysis included many covariates potentially associated with MA use rate compared to a total number of states $(n=49),{ }^{42}$ we performed a two-step analysis as follows: Pearson correlation analysis was conducted between MA use rate and the following state-level variables: mean altitude, population density, percentage under 18 year-old, percentage of White population, percentage of Black population, percentage of Hispanic population, percentage of $\mathrm{AI}$ and $\mathrm{AN}$ population, percentage of Asian population, median household income, persons aged 25 or over who are high school graduates, unemployment rate of 16 years of age over, same sex couples per 1000 households, MA laboratory incidents per 100,000 people, cocaine use rate, heroin use rate, marijuana use rate, alcohol use rate, tobacco use rate and nonmedical prescription pain relievers use rate. The variables which did not reach a significance level of $\mathrm{p}<0.05$ in relation to MA use were excluded from the model, and a multivariate linear regression analysis was conducted to analyze the effect of significant variables from the prior correlation analysis on the MA use rate.

All p-values are two-tailed, with $\mathrm{p}<0.05$ considered statistically significant. Statistical Analysis System (SAS), version 9.1 (SAS Institute Inc., Cary, NC, USA) was used for the computation.

\section{RESULTS}

As presented in Figure 2, there was a significant positive correlation between 12-month state-level MA use rate and mean state altitude (log-transformed) in the US ( $\mathrm{r}=0.66, \mathrm{p}<$ 0.0001). Simple linear regression analysis using MA use rate as the dependent variable and mean state altitude as an independent variable showed that state altitude (log-transformed) was a significant predictor for MA use $(\beta=0.66, \mathrm{p}<0.0001)$

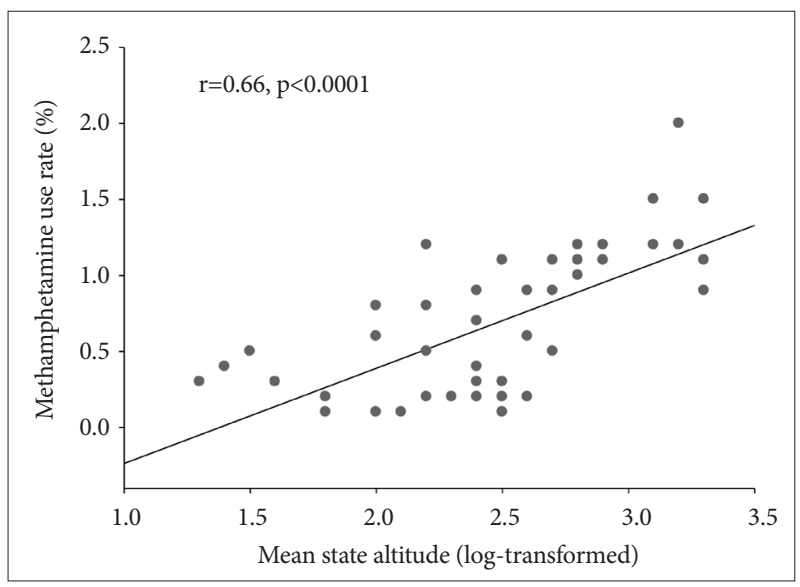

Figure 2. Correlation between mean altitude and methamphetamine use rate in the past year by state in the United States*. *based on 48 contiguous states and the District of Columbia (excludes Alaska and Hawaii).

(Table 1). In this model, the adjusted $R$ square value was 0.428 , suggesting that altitude accounts for a considerable proportion of the variance in regional variation in MA use.

The predictor variables that we found to be significantly related to MA use included the following: mean state altitude (log-transformed; $\mathrm{r}=0.66, \mathrm{p}<0.0001$ ), percentage under 18 yearold $(\mathrm{r}=0.42, \mathrm{p}=0.003)$, percentage of Black population ( $\mathrm{r}=$ $-0.37, \mathrm{p}=0.008)$, percentage of AI and AN population (logtransformed; $r=0.64, p<0.0001)$, MA laboratory incidents per 100,000 people (log-transformed; $\mathrm{r}=0.61, \mathrm{p}<0.0001$ ), and heroin use rate (log-transformed; $\mathrm{r}=-0.49, \mathrm{p}<0.0001$ ). Population density, percentage of White population, percentage of Hispanic population (log-transformed), percentage of Asian population, median household income, persons aged 25 or over who are high school graduates, unemployment rate of 16 years of age over, same sex couples per 1,000 households, cocaine use rate, marijuana use rate, alcohol use rate in the past month, tobacco use rate, and nonmedical prescription pain relievers use rate did not reach significance in relation to MA use and were therefore excluded from the multivariate linear regression analysis. In this regression analysis (Table 1) that controlled for the other significant variables, mean state altitude (log-transformed; $\beta=0.36 ; p=0.02$ ) remained a significant predictor of MA use. Consistent with the published literature in this area, the percentage of $\mathrm{AI}$ and $\mathrm{AN}$ population (log-transformed; $\beta=0.35, p=0.002$ ) and MA laboratory incident (log-transformed; $\beta=0.38, p=0.004$ ) were also found to be significant risk factors in this model. ${ }^{6,8,43,44}$ However, the percentage under 18 year-old, the percentage of Black population and the heroin use rate (log-transformed) were not found to predict MA use in this model. 
Table 1. Multivariate linear regression analysis predicting regional variation of MA use rate in US states

\begin{tabular}{|c|c|c|c|c|c|}
\hline \multirow[t]{2}{*}{ Predictors } & \multicolumn{2}{|c|}{$\begin{array}{c}\text { Unstandardized } \\
\text { coefficients }\end{array}$} & \multirow{2}{*}{$\begin{array}{c}\begin{array}{c}\text { Standardized } \\
\text { coefficients }\end{array} \\
\beta\end{array}$} & \multirow[t]{2}{*}{$\mathrm{t}$} & \multirow[t]{2}{*}{$\mathrm{p}$} \\
\hline & B & SE & & & \\
\hline (Constant) & -0.30 & 0.58 & & -0.52 & 0.60 \\
\hline Mean altitude* & 0.34 & 0.14 & 0.36 & 2.42 & 0.02 \\
\hline Percentage under 18 year-old & 0.01 & 0.03 & 0.03 & 0.26 & 0.80 \\
\hline Percentage of Black population & 0.01 & 0.01 & 0.06 & 0.46 & 0.65 \\
\hline Percentage of AI and AN population* & 0.37 & 0.11 & 0.35 & 3.23 & 0.002 \\
\hline MA laboratory incidents per 100,000 people* & 0.19 & 0.06 & 0.38 & 3.09 & 0.004 \\
\hline Heroin use rate & 0.08 & 0.24 & 0.05 & 0.34 & 0.73 \\
\hline Adjusted $\mathrm{R}^{2}=0.62$ & $\mathrm{~F}=13.87$ & $\mathrm{p}<0.0001$ & & & \\
\hline
\end{tabular}

*log-transformed. SE: standard error, AI: American Indian, AN: Alaska Native, MA: methamphetamine

\section{DISCUSSION}

Using U.S. national data at a state level, we found that selfreported past year MA use was significantly affected by altitude of residence, as well as MA manufacturing and distribution. Furthermore, the published literature regarding MA risk factors was reviewed, and available U.S. data for potential confounding variables was obtained and controlled for in these analyses. To our knowledge, this is the first such report in this area. These analyses add to our previous findings of altitude's association with completed suicide, major depressive episodes, and cocaine use..$^{30,45,46}$ The accumulated epidemiologic data suggest the need for further studies to investigate the mechanism of altitude's association with these clinical phenomena.

A distinctive environmental characteristic of increased altitude is hypobaric hypoxia. Prolonged exposure to hypoxia might lead to the changes in oxygen-dependent neurotransmission. Animal studies have demonstrated that prolonged exposure to hypobaric hypoxia causes elevation in DA and $\mathrm{NE}$ levels ${ }^{47}$ and increases the activity of tyrosine hydroxylase, which is the rate-limiting enzyme for catecholamine synthesis, in the cerebral cortex. ${ }^{48}$

There is increasing evidence showing that increased DA and decreased 5-HT levels in the brain may be linked to the vulnerability to cocaine and MA use. Chronic stress activates DA release and lowers 5-HT levels. ${ }^{49}$ Stress enhances craving for cocaine or MA, resulting in increased relapse rate in human drug abusers ${ }^{50,51}$ and increases the self-administration of psychostimulants in animal studies. ${ }^{18}$

Dopamine hyperactivity has been regarded as a mediating factor in sensation- or novelty- seeking personality ${ }^{52}$ as well as impulsive behavior, ${ }^{23}$ both of which are risk factors for MA use. Marusich et al. ${ }^{20}$ demonstrated that a multivariate assessment reflecting individual differences in sensation-seeking and impulsivity predicted acquisition, maintenance, and dose- effect measurements of amphetamine self-administration in rats. Iritani et al. ${ }^{53}$ showed that novelty-seeking characteristics were associated with greater likelihood of past year crystal MA use among young adults in the U.S. In addition, several clinical studies have suggested that MA users with a genetic predisposition toward elevated DA functioning are higher in novelty-seeking. ${ }^{21,22}$

Despite some controversies, ${ }^{54,55}$ previous epidemiological studies have consistently suggested that high altitude of residence might contribute to the increased incidence of psychiatric problems including suicide, ${ }^{46,56}$ severe psychological distress and major depressive episodes, ${ }^{45}$ and cocaine abuse. ${ }^{30}$ These phenomena are also closely associated with alterations of DA and 5-HT levels in the brain. ${ }^{57,58}$ MA use among youth has a consistent relationship with depression, and suicide likely contributes to increased morbidity and mortality among MA users. ${ }^{59}$ Further, positive correlations between MA use rate and mean state altitude are consistent with the increased rate of cocaine use, which has similar psychopharmacological properties.

Our finding that altitude of residence is a statistically significant predictor of MA use should be cautiously interpreted. Previous studies have suggested that MA use is affected by age, ethnicity, education, socioeconomic level, employment, and other substance abuse. ${ }^{6,32,33}$ Gonzales et al. ${ }^{5}$ emphasized that subpopulations including people who have same sex partners are at increased risk for MA use. In addition, MA laboratory incidents implicating MA manufacture and distribution should be not overlooked as a contributing factor of the variation in MA use. ${ }^{8}$ However, when we conducted additional analyses to control for the above variables, altitude remained a significant contributing factor of MA use.

Several limitations should be considered in interpreting our results. First, this study was based on state-level data, resulting in a modest sample size. Although there is considerable be- 
tween-state variation in altitude, within-state variation may be also anticipated. However, at present, substate- or countylevel MA use data is not available. Also, further studies are needed to investigate the relationship altitude and MA use at the individual level. Second, the relationship between altitude and MA use requires replication in other countries which have different social and cultural environments, but similar geographic variation, compared to the US Third, neurobiological investigation of altitude and hypobaric hypoxia's connection with MA use should be attempted in further studies.

In conclusion, we found that mean state altitude is positively correlated with the rate of MA use in the US and that this finding is robust to statistical adjustment for all of the available confounding variables. These results support the hypothesis that altitude accounts for a significant proportion of the regional variation of MA use in the US The available genetic epidemiology data indicate that environmental factors unique to each individual person determine which class of psychoactive drug they will use or misuse. ${ }^{11}$ Increased use of MA at altitude could be mediated by the hypoxic stress response, which preclinical studies show causes neuroadaptation in both brain DA levels and the hypothalamic-pituitary-adrenal axis. Further studies are needed to determine if, and how, the changes in neurotransmission resulting from altitude-associated hypobaric hypoxia play a role in MA use.

\section{Acknowledgments}

This project was supported by the VISN 19 MIRECC and the Utah Science Technology and Research Initiative (USTAR).

\section{REFERENCES}

1. Yamamoto BK, Moszczynska A, Gudelsky GA. Amphetamine toxicities: classical and emerging mechanisms. Ann NY Acad Sci 2010;1187: 101-121.

2. Volz TJ, Fleckenstein AE, Hanson GR. Methamphetamine-induced alterations in monoamine transport: implications for neurotoxicity, neuroprotection, and treatment. Addiction 2007;102(Suppl 1):44-48.

3. Watanabe-Galloway S, Ryan S, Hansen K, Hullsiek B, Muli V, Malone AC. Effects of methamphetamine abuse beyond individual users. J Psychoactive Drugs 2009;41:241-248.

4. Cunningham JK, Liu LM. Impacts of federal precursor chemical regulations on methamphetamine arrests. Addiction 2005;100:479-488.

5. Gonzales R, Mooney L, Rawson RA. The methamphetamine problem in the United States. Annu Rev Public Health 2010;31:385-398.

6. Hunt D, Kuck S, Truitt L. Methamphetamine Use: Lessons Learned. Cambridge: Abt Associates Inc.; 2006.

7. Maxwell JC, Rutkowski BA. The prevalence of methamphetamine and amphetamine abuse in North America: a review of the indicators, 19922007. Drug Alcohol Rev 2008;27:229-235.

8. Sudakin D, Power LE. Regional and temporal variation in methamphetamine-related incidents: applications of spatial and temporal scan statistics. Clin Toxicol (Phila) 2009;47:243-247.

9. McCann UD, Ricaute GA. Amphetamine (Or Amphetamine-Like)Related Disorders, 9th Edition. In: Sadock BJ, Sadock VA, Ruiz P, Editors. Kaplan and Sadock's Comprehensive Textbook of Psychiatry. Philadelphia: Lippincott Williams \& Wilkins, 2009, p.1288-1296.
10. Tata DA, Yamamoto BK. Interactions between methamphetamine and environmental stress: role of oxidative stress, glutamate and mitochondrial dysfunction. Addiction 2007;102(Suppl 1):49-60.

11. Kendler KS, Jacobson KC, Prescott CA, Neale MC. Specificity of genetic and environmental risk factors for use and abuse/dependence of cannabis, cocaine, hallucinogens, sedatives, stimulants, and opiates in male twins. Am J Psychiatry 2003;160:687-695.

12. Tsuang MT, Lyons MJ, Eisen SA, Goldberg J, True W, Lin N, et al. Genetic influences on DSM-III-R drug abuse and dependence: a study of 3,372 twin pairs. Am J Med Genet 1996;67:473-477.

13. Kumar GK. Hypoxia. 3. Hypoxia and neurotransmitter synthesis. Am J Physiol Cell Physiol 2011;300:C743-C751.

14. Flatmark T. Catecholamine biosynthesis and physiological regulation in neuroendocrine cells. Acta Physiol Scand 2000;168:1-17.

15. Hochachka PW, Monge C. Evolution of human hypoxia tolerance physiology. Adv Exp Med Biol 2000;475:25-43.

16. Ray K, Dutta A, Panjwani U, Thakur L, Anand JP, Kumar S. Hypobaric hypoxia modulates brain biogenic amines and disturbs sleep architecture. Neurochem Int 2011;58:112-128.

17. Robinson SM, Baumel IP, Blatt WF. The effect of simulated altitude exposure on the lethality of sympathomimetic amines. Toxicol Appl Pharmacol 1969;15:304-309.

18. Piazza PV, Le Moal ML. Pathophysiological basis of vulnerability to drug abuse: role of an interaction between stress, glucocorticoids, and dopaminergic neurons. Annu Rev Pharmacol Toxicol 1996;36:359-378.

19. Fillmore MT, Rush CR. Impaired inhibitory control in chronic cocaine abusers. Drug Alcohol Depend 2002;66:265-273.

20. Marusich JA, Darna M, Charnigo RJ, Dwoskin LP, Bardo MT. A multivariate assessment of individual differences in sensation seeking and impulsivity as predictors of amphetamine self-administration and prefrontal dopamine function in rats. Exp Clin Psychopharmacol 2011;19: 275-284.

21. Han DH, Yoon SJ, Sung YH, Lee YS, Kee BS, Lyoo IK, et al. A preliminary study: novelty seeking, frontal executive function, and dopamine receptor (D2) TaqI A gene polymorphism in patients with methamphetamine dependence. Compr Psychiatry 2008;49:387-392.

22. Hosák L, Libiger J, Cizek J, Beránek M, Cermáková E. The COMT Val158 Met polymorphism is associated with novelty seeking in Czech methamphetamine abusers: preliminary results. Neuro Endocrinol Lett 2006;27:799-802.

23. Pattij T, Vanderschuren LJ. The neuropharmacology of impulsive behaviour. Trend Pharmacol Sci 2008;29:192-199.

24. Soubrie P. Reconciling the role of central serotonin neurons in human and animal behavior. Behav Brain Sci 1986;9:319-364.

25. Akimoto K, Hamamura T, Kazahaya Y, Akiyama K, Otsuki S. Enhanced extracellular dopamine level may be the fundamental neuropharmacological basis of cross-behavioral sensitization between methamphetamine and cocaine - an in vivo dialysis study in freely moving rats. Brain Res 1990;507:344-346.

26. Bardo MT. Neuropharmacological mechanisms of drug reward: beyond dopamine in the nucleus accumbens. Crit Rev Neurobiol 1998;12: 37-67.

27. White FJ, Kalivas PW. Neuroadaptations involved in amphetamine and cocaine addiction. Drug Alcohol Depend 1998;51:141-153.

28. Volkow ND, Fowler JS, Wang GJ, Swanson JM, Telang F. Dopamine in drug abuse and addiction: results of imaging studies and treatment implications. Arch Neurol 2007;64:1575-1579.

29. Davidson C, Lee TH, Ellinwood EH. Acute and chronic continuous methamphetamine have different long-term behavioral and neurochemical consequences. Neurochem Int 2005;46:189-203.

30. Fiedler KK, Kim N, Kondo DG, Renshaw PF. Cocaine use in the past year is associated with altitude of residence. J Addict Med 2012;6:166171.

31. World drug report 2007. Available at: http://www.unodc.org/unodc/ en/data-and-analysis/WDR-2007.html. Accessed June 17, 2012. 
32. Herman-Stahl MA, Krebs CP, Kroutil LA, Heller DC. Risk and protective factors for methamphetamine use and nonmedical use of prescription stimulants among young adults aged 18 to 25. Addict Behav 2007; 32:1003-1015.

33. Russell K, Dryden DM, Liang Y, Friesen C, O’Gorman K, Durec T, et al. Risk factors for methamphetamine use in youth: a systematic review. BMC Pediatr 2008;28:8-48.

34. State estimates of past year methamphetamine use. 2006. Available at: http://www.oas.samhsa.gov/2k6/stateMeth/stateMeth.htm. Accessed May 13, 2012.

35. National Geospatial-Intelligence Agency, National Aeronautics and Space Administration. Shutte Radar Topography Mission (STRM) dataset. Souix Falls: United States Geological Survey; 2000.

36. National Atlas of the United States; County boundaries of the United States. 2001. Available at: http://www.nationalatlas.gov/metadata/ countyp020.html. Accessed May 13, 2012.

37. Johnston LD, O’Malley PM, Bachman JG, Schulenberg JE. Monitoring the Future National Survey Results on Drug Use, 1975-2004. Volume I: Secondary School Students (NIH Publication No. 05-5727). Bethesda: National Institute on Drug Abuse; 2005.

38. 2010 Census Data. 2010. Available at: http://2010.census.gov/2010census/ data/. Accessed May 13, 2012.

39. Local area unemployment statistics, 2010. Available at: http://www.bls. gov/lau/. Accessed May 13, 2012.

40. Methamphetamine lab incidents, 2004. Available at http://www.justice. gov/dea/concern/map_lab_seizures.html. Accessed May 13, 2012.

41. Gates GJ, Cooke AM. Washington Census Snapshot: 2010. Los Angeles: The Williams Institute; 2011.

42. Petrie A, Sabin C. Medical Statistical at a Glance. Oxford: Blackwell Publishing Ltd.; 2005.

43. Forcehimes AA, Venner KL, Bogenschutz MP, Foley K, Davis MP, Houck JM, et al. American Indian methamphetamine and other drug use in the Southwestern United States. Cultur Divers Ethnic Minor Psychol 2011;17:366-376.

44. Freese TE, Obert J, Dickow A, Cohen J, Lord RH. Methamphetamine abuse: issues for special populations. J Psychoactive Drugs 2000;32: 177-182.

45. DelMastro K, Hellem T, Kim N, Kondo D, Sung YH, Renshaw PF. Incidence of major depressive episode correlates with elevation of substate region of residence. J Affect Disord 2011;129:376-379.

46. Kim N, Mickelson JB, Brenner BE, Haws CA, Yurgelun-Todd DA, Renshaw PF. Altitude, gun ownership, rural areas, and suicide. Am J Psy- chiatry 2011;168:49-54.

47. Olson EB, Vidruk EH, McCrimmon DR, Dempsey JA. Monoamine neurotransmitter metabolism during acclimatization to hypoxia in rats. Respiratory Physiol 1983;54:79-96.

48. Gozal E, Shah ZA, Pequignot JM, Pequignot J, Sachleben LR, CzyzykKrzeska MF, et al. Tyrosine hydroxylase expression and activity in the rat brain: differential regulation after long-term intermittent or sustained hypoxia. J Appl Physiol (1985) 2005;99:642-649.

49. Chaouloff F, Bertom O, Mormede P. Serotonin and stress. Neuropsychopharmacology 1999;21(2 Suppl):28S-32S.

50. Sinha R, Garcia M, Palowal P, Kreek MJ, Rounsaville BJ. Stress-induced cocaine craving and hypothalamic-pituitary-adrenal responses are predictive of cocaine relapse outcomes. Arch Gen Psychiatry 2006;63:324331.

51. Soderpalm A, Nikolayev L, de Wit H. Effects of stress on responses to methamphetamine in humans. Psychopharmacology (Berl) 2003;170: 188-199.

52. Cloninger CR. A systematic method for clinical description and classification of personality variants: A proposal. Arch Gen Psychiatry 1987; 44:573-588.

53. Iritani BJ, Hallforsm DD, Bauer DJ. Crystal methamphetamine use among young adults in the USA. Addiction 2007;102:1102-1113.

54. Betz ME, Valley MA, Lowenstein SR, Hedegaard H, Thomas D, Stallones L, et al. Elevated suicide rates at high altitude: sociodemographic and health issues may be to blame. Suicide Life Threat Behav 2011;41: 562-573.

55. Selek S. Altitude, immigration and suicide rates: a study from Turkey. Psychiatry Investig 2013;10:89-91.

56. Brenner B, Cheng D, Clark S, Camargo CA Jr. Positive association between altitude and suicide in 2584 U.S. counties. High Alt Med Biol 2011;12:31-35.

57. Cox SM, Benkelfat C, Dagher A, Delaney JS, Durand F, Kolivakis T, et al. Effects of lowered serotonin transmission on cocaine-induced striatal dopamine response: PET $\left[{ }^{11} \mathrm{C}\right]$ raclopride study in humans. Br J Psychiatry 2011;199:391-397.

58. Ryding E, Lindström M, Träskman-Bendz L. The role of dopamine and serotonin in suicidal behaviour and aggression. Prog Brain Res 2008; 172:307-315.

59. Marshall BD, Werb D. Health outcomes associated with methamphetamine use among young people: a systematic review. Addiction 2010; 105:991-1002. 